\title{
Comunicação
}

[Communication]

\section{Comparação da eficiência dos caldos de enriquecimento seletivo no isolamento de Salmonella Dublin}

\author{
[Comparison of the efficiency of selective enrichment broths for Salmonella Dublin isolation] \\ D.G. Silva ${ }^{1}$, J.J. Fagliari ${ }^{*}$, T.B. Garcia ${ }^{1}$ \\ ${ }^{1}$ Aluno de pós-graduação - FCAV-UNESP - Jaboticabal, SP \\ ${ }^{2}$ Faculdade de Ciências Agrárias e Veterinárias - UNESP -Jaboticabal, SP \\ Via de Acesso Prof. Paulo Donato Castellane, $\mathrm{s} / \mathrm{n}$ \\ 14884-900 - Jaboticabal, SP
}

A salmonelose constitui uma das principais causas de morbidade e mortalidade em bezerros, sendo a Salmonella Dublin e a Salmonella Typhimurium os sorotipos mais freqüentemente isolados na espécie bovina (Santos et al., 2002; Veling et al., 2002).

Os procedimentos microbiológicos para o isolamento de Salmonella de amostras de fezes geralmente incluem etapas de préenriquecimento, enriquecimento em caldo seletivo, plaqueamento em meio semi-sólido, análise bioquímica e sorotipificação (Litchfield, 1973). As etapas de enriquecimento em caldo seletivo e plaqueamento em meios semi-sólidos são utilizadas para auxiliar na recuperação e no desenvolvimento da bactéria de interesse e para inibir o crescimento de microrganismos competidores (Fernandes et al., 2004).

Segundo Waltman (1998), há três tipos de meios de enriquecimento: caldo Rappaport-Vassiliadis, caldo selenito e caldo tetrationato. A escolha do melhor caldo para detecção ou recuperação de Salmonella de amostras de fezes muitas vezes é difícil devido, principalmente, à falta de resultados conclusivos a esse respeito (Freschi et al., 2005; Paiva et al., 2006).

O objetivo do presente estudo foi avaliar a eficiência dos caldos de enriquecimento seletivos
Rappaport-Vassiliadis, selenito cistina e tetrationato Muller-Kauffmann no isolamento ou na recuperação de Salmonella Dublin de amostras de fezes de bezerro experimentalmente infectado, de modo a facilitar a escolha do meio mais apropriado.

Foram analisadas 14 amostras de fezes obtidas por meio de suabes retais de bezerro macho da raça Holandesa, com 15 dias de idade, infectado experimentalmente com $10^{8}$ unidades formadoras de colônia de Salmonella Dublin (Fecteau et al., 2003). As amostras foram colhidas em triplicata, imediatamente antes da inoculação (A0) e a intervalos de 12 horas, ao longo de sete dias após a infecção experimental (A1 a A13).

Para o isolamento de Salmonella Dublin, foram testados três caldos de enriquecimento seletivo: Rappaport-Vassiliadis (RV), selenito cistina (SC) e tetrationato Muller-Kauffmann (TMK). Também foi avaliada a temperatura de incubação do caldo $\mathrm{RV}, 37^{\circ} \mathrm{C}$ (RV37) e $42^{\circ} \mathrm{C}$ (RV42).

Das três amostras de suabes retais colhidas em um mesmo momento, duas amostras foram diretamente inoculadas em $10 \mathrm{ml}$ de caldo SC (Oxoid CM 699) e TMK (Oxoid CM 343) e incubadas a $37^{\circ} \mathrm{C}$ durante 24 horas. A outra amostra foi inicialmente pré-enriquecida em 10ml de caldo GN-Hajna (Difco 0486-17) e

Recebido em 16 de maio de 2007

Aceito em 4 de abril de 2008

*Autor para correspondência (corresponding author)

E-mail: fagliari@fcav.unesp.br 
incubada a $37^{\circ} \mathrm{C}$ por 24 horas. Após o crescimento, transferiu-se $0,1 \mathrm{ml}$ para dois tubos que continham 9,9ml de caldo $\mathrm{RV}$ (Oxoid $\mathrm{CM}$ 866) que foram incubados a $37^{\circ} \mathrm{C}$ e a $42^{\circ} \mathrm{C}$ durante 24 horas. Após incubação, os caldos foram semeados em placas contendo ágar verde brilhante modificado (Oxoid CM 329) e incubados a $37^{\circ} \mathrm{C}$ por 24 horas. De cada placa, três colônias sugestivas de bactérias do gênero Salmonella foram inoculadas em tubos contendo ágar tríplice açúcar e ferro (Oxoid CM 277) e ágar lisina ferro (Oxoid CM 381). Todas as colônias identificadas presuntivamente como Salmonella foram submetidas ao teste de soroaglutinação em lâmina, com soro polivalente antiantígenos somáticos (O) e com soro polivalente antiantígenos flagelares $(\mathrm{H})$ de Salmonella.

Os resultados obtidos foram analisados estatisticamente pelo teste McNemar (Zar, 1999).

Diferenças significativas $(\mathrm{P}<0,05)$ foram encontradas entre os caldos de enriquecimento usados na recuperação de Salmonella Dublin de amostras de fezes. Todas as amostras colhidas após a infecção experimental foram positivas para Salmonella Dublin após cultivo em caldo SC, enquanto somente $69 \%(9 / 13)$ das amostras foram positivas quando se utilizou o caldo TMK (Tab. 1). Este resultado confirma os descritos por Forward e Rainnie (1997) e Alvseiek e Skjerve (2000) que relataram bons resultados com o uso do caldo SC na recuperação de Salmonella das fezes. Por outro lado, Freschi et al. (2005) verificaram melhor rendimento com a utilização do caldo TMK. O caldo RV apresentou o pior desempenho dentre os caldos avaliados no isolamento microbiológico, detectando apenas $23 \%$ (3/13, RV37) e 8\% (1/13, RV42) de amostras positivas. Apesar de o caldo RV ser um meio de alta seletividade (Paiva et al., 2006), Peterz et al. (1989) relataram que a temperatura de incubação de $42^{\circ} \mathrm{C}$ pode inibir o crescimento de Salmonella Dublin. As amostras colhidas antes da inoculação foram negativas para Salmonella Dublin em todos os caldos avaliados.

Desse modo, os resultados obtidos mostraram que o caldo SC foi a melhor opção de enriquecimento seletivo para o isolamento ou recuperação de Salmonella Dublin de amostras de fezes de bezerro.

Tabela 1. Resultados do isolamento de Salmonella Dublin em amostras de fezes de bezerro infectado experimentalmente, utilizando-se os caldos de enriquecimento seletivo Rappaport-Vassiliadis incubado a $37^{\circ} \mathrm{C}$ (RV37), Rappaport-Vassiliadis incubado a $42^{\circ} \mathrm{C}$ (RV42), selenito cistina (SC) e tetrationato MullerKauffmann (TMK).

\begin{tabular}{ccccc}
\hline \multirow{2}{*}{ Amostras } & \multicolumn{5}{c}{ Caldos de enriquecimento seletivo } \\
\cline { 2 - 5 } A0 & RV37 & RV42 & SC & - \\
A1 & - & - & + & - \\
A2 & + & - & + & - \\
A3 & + & - & + & - \\
A4 & - & - & + & + \\
A5 & + & - & + & + \\
A6 & - & + & + & + \\
A7 & - & - & + & - \\
A8 & - & - & + & + \\
A9 & - & - & + & + \\
A10 & - & - & + & + \\
A11 & - & - & + & + \\
A12 & - & - & + & + \\
A13 & - & - & 13 & 9 \\
\hline Total & - & 1 & + \\
\hline
\end{tabular}

+ : positivo para Salmonella Dublin; - : negativo para Salmonella Dublin.

Palavras-chave: bezerro, Salmonella Dublin, meio seletivo, fezes 


\begin{abstract}
The aim of this study was to compare three different selective enrichment broths: Rappaport-Vassiliadis $(R V)$, selenite cystine (SC) and Muller-Kauffmann tetrathionate (MKT) for Salmonella Dublin isolation from faecal samples of calf experimentally infected. The bacteriological procedure involved preenrichment stages in Hajna-GN broth (only for the samples inoculated in RV broth), selective enrichment, culture in modified brilliant green agar (BGA), presumptive biochemistry tests (using triple-sugar-iron agar and lysine-agar) and slide agglutination test with poli-O and poli-H Salmonella antiserum. The effects of enrichment temperatures using $R V$ broth were also evaluated $\left(37^{\circ} \mathrm{C}\right.$ and $\left.42^{\circ} \mathrm{C}\right)$. SC broth was significantly more efficient in the isolation of Salmonella Dublin $(P<0,05)$, whereas $R V$ broth incubated at $42^{\circ} \mathrm{C}$ had a lower efficiency in the microbiological isolation.
\end{abstract}

Keywords: Salmonella Dublin, selective enrichment, calves, feces

\section{AGRADECIMENTOS}

Os autores agradecem à FAPESP pela concessão de bolsa e auxílio financeiro e à Fundação Oswaldo Cruz-FIOCRUZ pelo fornecimento da cepa de Salmonella Dublin.

\section{REFERÊNCIAS BIBLIOGRÁFICAS}

ALVSEIKE, O.; SKJERVE, E. Probability of detection of Salmonella using different analytical procedures, with emphasis on subspecies diarizonae serovar 61:k:1,5,(7) [S. IIIb 61:k:1,5,(7)]. Int. J. Food. Microbiol., v.58, p.49-58, 2000.

FECTEAU, M.V.; HOUSE, J.K.; KOTARSKI, S.F. et al. Efficacy of ceftiofur tratament of experimental salmonellosis in neonatal calves. Am. J. Vet. Res., v.64, p.918-925, 2003.

FERNANDES, A.C.; BERCHIERI Jr., A.; OLIVEIRA, G.H. et al. Avaliação de meios de cultivo para o isolamento de Salmonella. Ars Vet., v.20, p.330-337, 2004.

FORWARD, K.R.; RAINNIE, B.J. Use of selenite enrichment broth for the detection of Salmonella from stool: a report of one year experience at a provincial public health laboratory. Diagn. Microbiol. Infect. Dis., v.29, p.215-217, 1997.

FRESCHI, C.R.; CARVALHO, L.F.O.S.; OLIVEIRA, C.J.B. Comparison of DNAextraction methods and selective enrichment broths on the detection of Salmonella Typhimurium in swine feces by polymerase chain reaction (PCR). Braz. J. Microbiol., v.36, p.363-367, 2005.
LITCHFIELD, J.H. Salmonella and the food industry: methods for isolation, identification and enumeration. Crit. Rev. Food Technol., v.3, p.415-456, 1973.

PAIVA, J.B.; STERZO, E.V.; RIBEIRO, S.A. et al. Isolamento de Salmonella: comparação das etapas de pré-enriquecimento e enriquecimento direto de amostras de fezes armazenadas por 24 e 96 horas. Arq. Inst. Biol., v.73, p.263-269, 2006.

PETERZ, M.; WIBERG, C.; NORBERG, P. The effect of incubation temperature and magnesium chloride concentration on growth of Salmonella in home-made and commercially available dehydrated Rappaport-Vassiliadis broths. $J$. Appl. Bacteriol., v.66, p.523-528, 1989.

SANTOS, R.L.; TSOLIS, R.M.; BAÜMLER, A.J. et al. Hematologic and serum biochemical changes in Salmonella ser Typhimuriuminfected calves. Am. J. Vet. Res., v.63, p.11451150, 2002.

VELING, J.; BARKEMA, H.W.; SCHANS, I. et al. Herd-level diagnosis for Salmonella enterica subsp enterica serovar Dublin infection in bovine dairy herds. Prev. Vet. Med., v.53, p.3142, 2002.

WALTMAN, W.D. Isolation of Salmonella from poultry environments. In: INTERNATIONAL SYMPOSIUM ON FOODBORNE SALMONELLA IN POULTRY, 1998, Baltimore. Proceedings... Baltimore, 1998. p.133-153.

ZAR, J.H. Biostatistical analysis. 4.ed. New Jersey: Prentice-Hall, 1999. 663p. 